University of Nebraska - Lincoln

DigitalCommons@University of Nebraska - Lincoln

$5-1-1991$

\title{
THERMAL DESORPTION OF Hg MONOLAYERS FROM Cu(100)
}

Y.J. Kime

Syracuse University

Jiandi Zhang

Syracuse University, jiandiz@lsu.edu

Peter A. Dowben

University of Nebraska-Lincoln, pdowben@unl.edu

Follow this and additional works at: https://digitalcommons.unl.edu/physicsdowben

Part of the Physics Commons

Kime, Y.J.; Zhang, Jiandi; and Dowben, Peter A., "THERMAL DESORPTION OF Hg MONOLAYERS FROM Cu(100)" (1991). Peter Dowben Publications. 154.

https://digitalcommons.unl.edu/physicsdowben/154

This Article is brought to you for free and open access by the Research Papers in Physics and Astronomy at DigitalCommons@University of Nebraska - Lincoln. It has been accepted for inclusion in Peter Dowben Publications by an authorized administrator of DigitalCommons@University of Nebraska - Lincoln. 


\title{
THERMAL DESORPTION OF Hg MONOLAYERS FROM Cu(100)
}

\author{
Y.J. KIME, JIANDI ZHANG, AND P.A. DOHBEN \\ Department of Physics, 201 Physics Building, Syracuse Oniversity, \\ Syracuse, NY 13244-1130
}

\section{ABSTRACT}

A two dimensional phase transition from one adlayer structure to another is an inherent part of the thermal desorption of one monolayer of $\mathrm{Hg}$ on $\mathrm{Cu}(100)$. The energetics of this phase transition have been studied using thermal desorption spectroscopy (TDS). The TDS spectra reflect the coexistence of the two structural phases for a range of $\mathrm{Hg}$ exposures. The TDS spectra have been analyzed within a Polanyi-Wigner framework modified to account for the phase transition.

\section{INTRODUCTION}

Two dimensional phase transitions of metal overlayers have been given increasing attention [1-3]. The energetics of these two dimensional transitions are typically very difficult to characterize because of the large heats of adsorption and complications of interdiffusion common to most metal overlayers $[4,5]$. Understanding of two dimensional phase transitions is, nonetheless, incomplete without a model of the energetics $[3,6]$.

Since mercury overlayers can be weakly adsorbed on many substrates [7] including $\mathrm{Cu}(100)$, such metal overlayers provide a unique opportunity for exploring two dimensional phase transitions. Hercury overlayers on $\mathrm{Cu}(100)$ have been recently characterized [7-11] and have been shown to exhibit two distinct submonolayer phases $[7,8,10]$. In this paper we demonstrate that the heat of desorption for $\mathrm{Hg}$ on $\mathrm{Cu}(100)$ is sufficiently small to permit the successful application of thermal desorption spectroscopy to the investigation of the phase transition in much the same way as has been attempted with reakly chemisorbed overlayers such as $\mathrm{N}_{2}$ and $\mathrm{CO}$ on nickel $[12-14]$.

\section{EXPERIMENTAL}

Thermal desorption studies were performed in a stainless steel UHV chamber with a base pressure of $1 \times 10^{-10}$ torr. The sample was mounted on a liquid nitrogen filled cold finger providing sample cooling to $120 \mathrm{~K}$. The $\mathrm{Cu}$ crystal was cleaned by repeated cycles of $500 \mathrm{eV} \mathrm{Ar}$ ion bombardment followed by annealing to maintain a well ordered (100) surface. Hg was admitted to the chamber at pressures at or below $5 \times 10^{-8}$ torr to prevent amalgamation with the Cu surface. Mercury pressure was monitored with a Dycor mass spectrometer during the thermal desorption. Total pressure was measured with a VG ion gauge. All pressures and exposures reported are uncorrected for ion gauge cross-section. The temperature of the sample was measured by a chromel-alumel thermocouple.

For the spectra reported in this paper, mercury adsorption was done at a sample temperature of $200 \mathrm{~K}$ but no lover. This permits us to restrict this study to the equilibrium phases $[7,8]$. The sample was then cooled to a temperature of $120 \mathrm{~K}$ prior to desorption. Thermal desorption spectra were also taken following adsorption at $120 \mathrm{~K}$ which will be published elsewhere 
[15]. Coverage determination with exposure and adsorption temperature has been studied extensively with LEED and ABS and is reported elsewhere [7].
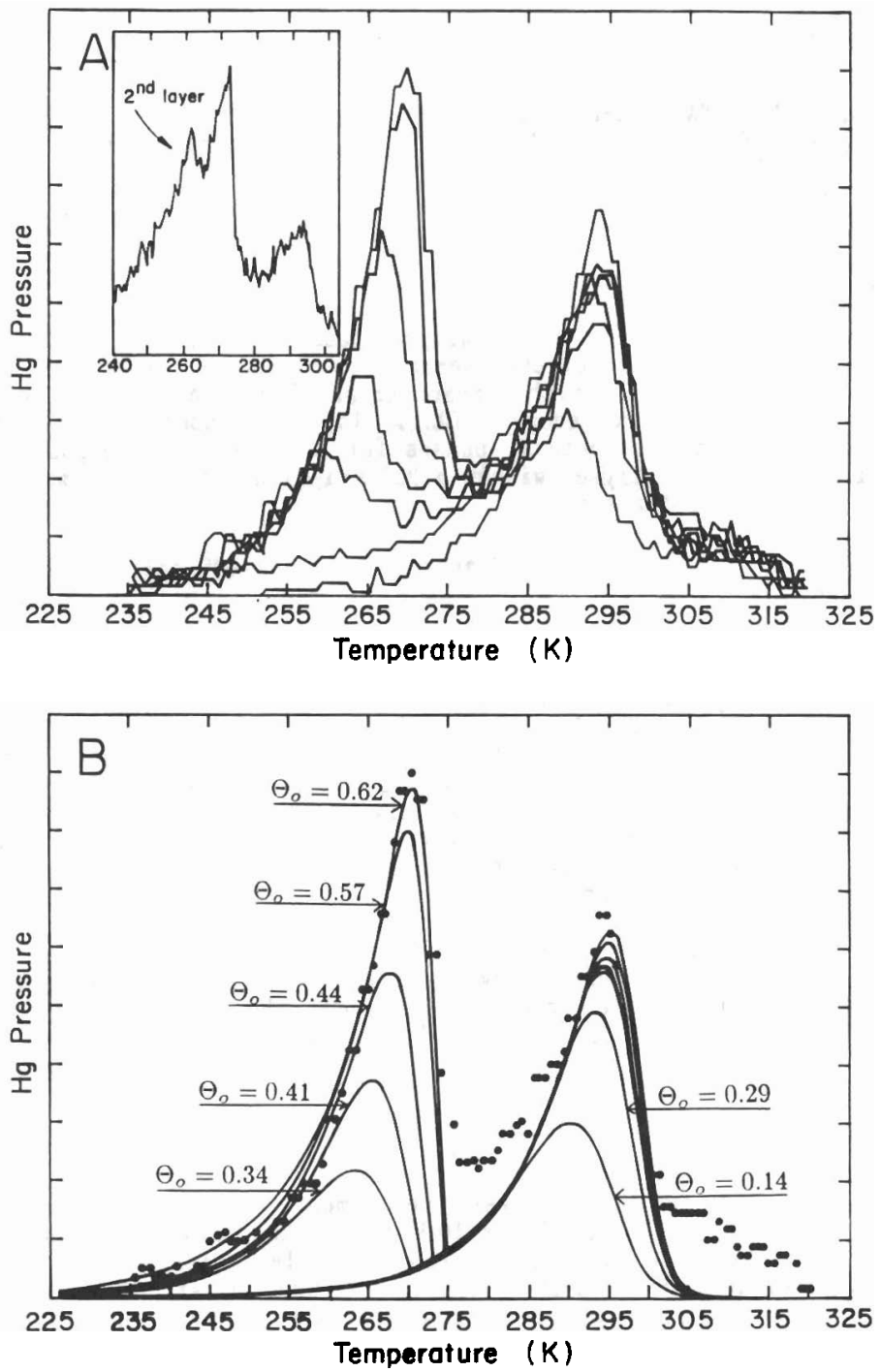

Figure 1A. TDS spectra for coverages up to one monolayer of $\mathrm{Hg}$ on $\mathrm{Cu}(100)$ at a desorption rate of $6.6 \mathrm{~K} / \mathrm{s}$. 1B. Theoretical curves fit using $E_{0}=0.70 \mathrm{eV}$ and $\mathrm{V}=-0.13 \mathrm{eV}$ for the low temperature peak and $\mathrm{E}_{0}=0.743$ $\mathrm{eV}$ and $\mathrm{V}=-0.21 \mathrm{eV}$ for the high temperatare peak. (•) are data fron the highest coverage curve in 14 . 


\section{RESULTS}

The thermal desorption spectra for a range of exposures of $\mathrm{Hg}$ on $\mathrm{Cu}(100)$ at a heating rate of $6.6 \mathrm{~K} / \mathrm{s}$ is shown in figure $1 \mathrm{~A}$. Following an initial exposure of $3.8 \mathrm{~L}\left(1 \mathrm{~L}=10^{-6}\right.$ torr $\left.\mathrm{s}\right)$ of $\mathrm{Hg}$ only one TDS peak at 290 $\mathrm{K}$ is observed. For a $9.4 \mathrm{~L}$ exposure a second peak is seen at $260 \mathrm{~K}$ and the higher temperature peak has shifted to $292 \mathbb{R}$. By an exposure of $15 \mathrm{~L}$ the lower temperature peak has shifted to $270 \mathrm{~K}$ and the higher temperature peak has shifted to about $294 \mathrm{~K}$. Higher exposures (up to $38 \mathrm{~L}$ ) lead to little change in the TDS spectra, although a small additional feature is seen on the lover temperature edge of the $270 \mathbb{R}$ peak, due to growth in a second layer. Some spectra can show a significant contribution from the second layer as a result of slightly lower adsorption temperatures. It is known, however from LEED and ABS that the second layer does not grow unless the adsorption temperature is lowered $[7,8]$.

Figure 2 shows the development of the two peaks with increasing initial exposure. The upper curve is determined by the integrated area under both peaks and so reflects the total coverage. The lower curve is the area under the higher temperature peak and so reflects the coverage which desorbs from that phase. The difference between the two curves, then, reflects the area under the low temperature peak. For coverages greater than $0.62 \mathrm{Hg}$ atoms per surface Cu atom, a small lower temperature peak is observed, believed to be a contribution from a second layer.

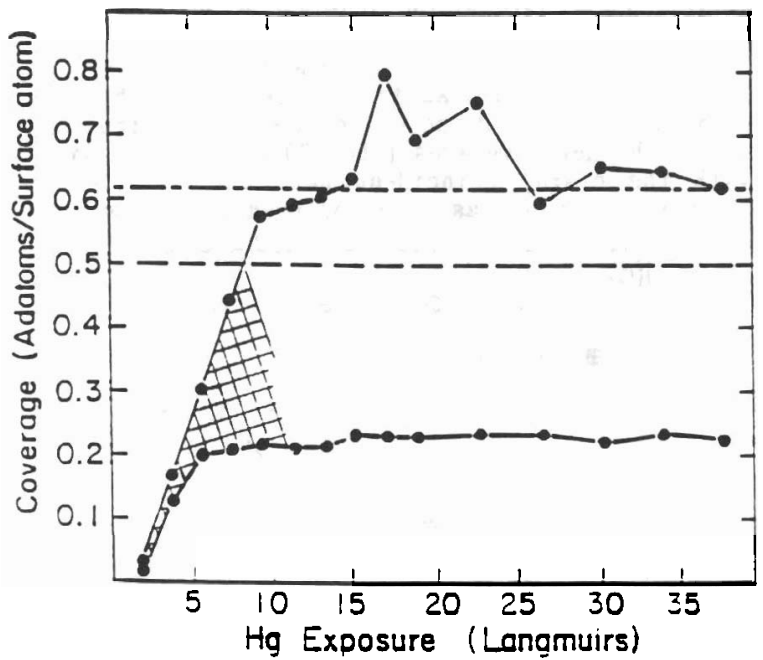

Figure 2. Upper curve reflects the total area of the TDS peak versus exposure. Lover curve reflects the area under the higher temperature peak only (the $c(2 \times 2)$ structure). Dashed line corresponds to saturation of the $c(2 \times 2)$ structure; dot-dashed line corresponds to saturation of the $c(4 \times 4)$ structure. Cross-hatched area is area of the coexistence of the tro phases during adsorption.

Similar sets of TDS spectra have been taken over a range of heating rates from $3.5 \mathrm{~K} / \mathrm{s}$ to $18.1 \mathrm{~K} / \mathrm{s}$. The overall shape of the TDS curves and the changes with increasing coverage seen in figure $1 \mathrm{~A}$ are typical of data over 
all of the heating rates. For all heating rates the lover coverage curves are shifted to lower temperatures with respect to the saturated overlayer peak.

. The positions of the TDS features and to a lesser extent the width of the peaks do exhibit consistent shifts with increasing heating rate. The lower temperature saturated peak shifts roughly linearly, shifting nearly a degree higher in temperature for every $1 \mathrm{k} / \mathrm{s}$ increase in heating rate. The higher temperature peak shifts about $0.7 \mathrm{~K}$ higher for every $1 \mathrm{k} / \mathrm{s}$ increase in heating rate. The width of the lower temperature peak increases about $40 \%$ over the range of heating rates measured while the higher temperature peak increases only about $25 \%$ over the range of heating rates $(3.5 \mathrm{~K} / \mathrm{s}$ to 18.1 $\mathrm{K} / \mathrm{s}$ ).

\section{DISCUSSION}

Earlier studies of $\mathrm{Hg}$ on $\mathrm{Cu}(100)$ using atom beam scattering (ABS) and low energy electron diffraction (LEBD) [7] have identified two adlayer structural phases for the same adsorption temperature as the present study. These structures are shown in figure 3 . The low coverage phase has a $c(2 \times 2)$ structure which corresponds to a saturation coverage of $0.5 \mathrm{Hg}$ adatoms per $\mathrm{Cu}$ surface atom. At higher exposures a second phase can be identified which has a coincident net structure (circled crosses) of a $c(4 \times 4)$ adlayer. This higher coverage phase has a saturation coverage of 0.62 adatoms per surface atom.

We can therefore assign the observed peaks in the TDS spectra to the different structural phases. The peak first observed at the lower coverages (the $290 \mathrm{~K}$ peak in figure $1 \mathrm{~A}$ corresponds to the $\mathrm{c}(2 \times 2)$ structure phase. The peak observed only at higher coverages (the $270 \mathrm{~K}$ peak) likewise corresponds to the phase with the $c(4 \times 4)$ coincident net. The shoulder around $310 \mathrm{~K}$ corresponds to defect states as has been observed vith atom beam scattering $[7,8]$.

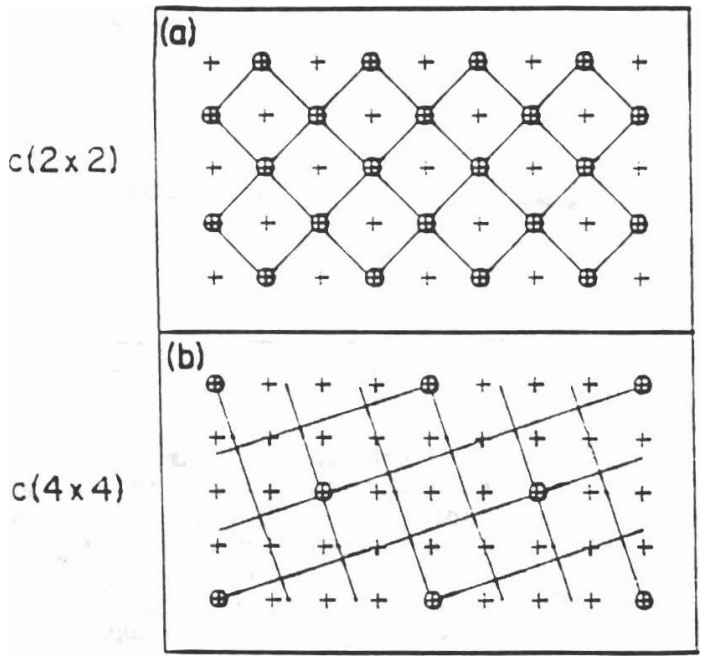

Figure 3. $c(2 \times 2)$ and $c(4 \times 4)$ overlayer structures. $(+)$ represent surface $\mathrm{Cu}$ atons; Hg atons are indicated by the intersection of the overlaying lines. indicates coincident net fron shich the $c(2 \times 2)$ and $c(4 \times 4)$ nonenclature is derived. 
The completely saturated monolayer is therefore in a $c(4 \times 4)$ structure. Initial desorption of $\mathrm{Hg}$ from the $\mathrm{Cu}(100)$ surface early in the thermal desorption process is necessary for the evacuation of sufficient space on the surface to permit relaxation to the less dense $c(2 \times 2)$ structure. The thermal desorption process, therefore, for this system, includes a phase transition from the more dense $c(4 \times 4)$ phase to the less dense $c(2 \times 2)$ phase.

As ve see in figure 2 , the coverage increases linearly with exposure for the first $9.4 \mathrm{~L}$, nearly to saturation of the $c(4 \times 4)$ adlayer (from comparison with LEED and ABS [7]). This is a clear indication of the existence of a long lived precursor state to adsorption $[16,17]$. This is important, especially when fitting the data with theoretical models.

The lover curve in figure 2 , derived from the $c(2 \times 2)$ TDS peak, levels off at a coverage of 0.23 , well below the saturated $c(2 \times 2)$ coverage of 0.50 . It is also clear that initial coverage adopts the $c(2 \times 2)$ structure, since the difference between the two curves (which reflects the area under the c (4x4) peak) is very small for the first $3 \mathrm{~L}$ of exposure. Since we observe c $4 \times 4$ structure at lower exposures than would saturate the (lower coverage) c $(2 \times 2)$ structure, both phases must coexist on the surface prior to desorption, othervise we would observe only the $c(2 \times 2)$ peak for total coverages less than 0.5 . The region of coexistence of these two phases is shown by the hatched area in figure 2 .

The coexistence of phases during the desorption process, on the other hand, comes about because the phase transition from the $c(4 \times 4)$ structure to the $c(2 \times 2)$ structure takes place over a range of temperatures, dictated by the mobility of the Hg adatoms.

To determine the desorption energies and the lateral interaction the data has been analyzed within a Polanyi-Vigner framevork [18], modified to account for the phase transition. Briefly, the coverage in phase $i$ at a temperature $\mathrm{T}$ is modeled by

$$
\theta_{\mathrm{i}}=\theta_{\mathrm{i} 0}-\int_{0}^{\mathrm{T}} \nu_{0}\left(\frac{\Theta_{\mathrm{i}}}{0.62-\Theta}\right) \exp \left(-\mathrm{E}_{\mathrm{di}} / \mathrm{k}_{\mathrm{B}} \mathrm{T}^{\prime}\right) \pm \lambda \mathrm{e}^{\tau / \mathrm{T}^{\prime}}\left(\Theta_{0}-\theta\right) \mathrm{d} \mathrm{T}^{\prime}
$$

where $\theta_{i o}$ is the initial coverage for that phase, $\theta_{0}$ is the total initial coverage, and $\theta$ is the total coverage at any temperature. The first term, the initial coverage in phase $i$, must reflect the coexistence of phases during adsorption for exposures below saturation. At saturation of the first monolayer $\theta_{c(4 \times 4) 0}=0.62$ and $\theta_{c(2 \times 2) 0}=0$.

The first term in the integral is the Polanyi-Vigner relation where $v_{0}$ is the pre-exponential factor, the term in parentheses accounts for the precursor, $k_{B}$ is Boltzman's constant, and $E_{d i}=E_{0 i}-V_{i} \Theta_{i}[19] . W_{i}$ is the energy of the lateral interaction, negative for attractive interactions and positive for repulsive interactions betreen adatoms.

The second term in the integral accounts for the phase transition from $c(4 \times 4)$ to $c(2 \times 2)$, so that for $i=c(4 \times 4)$ the term is added and for $i=c(2 \times 2)$ the term is subtracted. This term reflects the expectation that the fraction of coverage changing from a $c(4 \times 4)$ structure to a $c(2 \times 2)$ structure vould depend on the amount of space available (recall that the $c(2 \times 2)$ structure is less dense) and that the mobility of the $\mathrm{Hg}$ adatoms vould increase exponentially in temperature.

With this model for the phase transition and the desorption the energies $E_{0 i}$ and $V_{i}$ can be determined by the best fit to the data. Since a range of values of $E_{o}$ and $V$ can be used to fit any one spectra it is important that the best $\mathrm{fit}$ is determined over sets of data covering a range of initial coverages and desorption heating rates. For the $c(4 \times 4)$ phase we determined that $E_{0}=0.70 \mathrm{eV}$ and $V=-0.13 \mathrm{eV}$. Simuitaneous analysis of the $c(2 \times 2)$ peak gave $E_{0}=0.743 \mathrm{eV}$ and $\mathrm{V}=-0.21 \mathrm{eV}$. For the $c(2 \times 2)$ phase $E_{0}$ is larger and $W$ is smaller than the equilibrium isosteric heat of adsorption 
$\left(E_{0}=0.5 \mathrm{eV}\right.$ and $\mathrm{V}=-0.41 \mathrm{eV}[8]$ ) as expected. This implies a barrier to desorption and is consistent with the long lived precursor to adsorption discussed earlier. A more complete description of this analysis and analysis using different models for the phase transition will be published elsewhere $[15]$.

\section{CONCLUSIONS}

We have determined that for one monolayer of $\mathrm{Hg}$ on $\mathrm{Cu}(100)$ the zero coverage limit of the desorption energy is $0.70 \mathrm{eV}(0.743 \mathrm{eV})$ for the $c(4 \times 4)$ (c $(2 \times 2)$ ) phase and the lateral interactions are $-0.13 \mathrm{eV}$ and $-0.21 \mathrm{eV}$ for the $c(4 \times 4)$ and $c(2 \times 2)$ phases respectively. He have shown that thermal desorption spectroscopy can be used to glean structural information, such as the coexistence of phases. Further, we have proposed a theoretical framework for the analysis of thermal desorption processes which include a phase transition from one structure to another.

\section{ACRNOULEDGEMENTS}

This work was funded by the NSF through grant no. DUR-8820779.

\section{REFERENCES}

[1] E. Bauer, Appl. Phys. A51, 71 (1990).

2. P. Kleban and R. Hentschke, Phys. Rev. B37, 5738 (1988).

3. D.A. Browne and P. Kleban, Phys. Rev. 140,1615 (1989).

44 P.A. Dowben in Surface Segregation Phenomena, edited by P.A. Dowben and A. Hiller (CRC Press, Boca Raton, 1990) p.145.

[5] V.F. Egelhoff, Jr. Mater. Res. Soc. Symp. Proc. $\underline{83}, 189$ (1987).

6. A.R. Miedema and J.Y.F. Dorleijn, Phil. Mag. B43, 251 (1981).

[7] P.A. Dowben, Y.J. Kime, C.V. Hutchings, Vei Li, and G. Vidali, Surf. Sci. 230, $113(1990)$, and references therein.

[8] C.W. Hutchings, P.A. Dowben, Y.J. Rime, H. Li, M. Karimi, C. Moses. and G. Vidali, Proc. Mat. Res. Soc. Symp. 159, 133 (1990).

[9] P.A. Dowben, Y.J. Kime, D. LaGraffe, and M. Onellion, Surf. and Interface Anal. 15, 163 (1990).

[10] P.A. Dowben, D. LaGraffe, Dongqi Li, G. Vidali, L. Zhang, L. Dottl, and H. Onellion, Phys. Rev. B in press.

[11] Shikha Varma, Y.J. Kime, D. LaGraffe, P.A. Dowben. H. Onellion. and J.L. Erskine, J. Chem. Phys. 93, 2819 (1990).

[12] Shikha Varma and P.A. Dowben, J. Vac. Sci. Technol. A8, 2605 (1990).

131 II. Golze, H. Grunze, and V. Hirschvald, Vacuum 31, 697 (1981).

14. Holze, M. Grunze, and V. Unertl, Prog. Surf. Sci. 22, 101 (1986).

15. Y.J. Kime, P.A. Dowben, J. Zhang, and L. Zhang, in preparation.

16. G. Ehrlich, J. Phys. Chem. 59, 473 (1955).

17. G. Ehrlich, J. Phys. Chem. Solids, 1,3 (1956).

[18. P.A. Redhead, J.P. Hobson, and E.V. Kornelson, "The Physical Basis of Uitrahigh Vacuun", Chapman and Hail, London (1968).

[19] J.W. Niemantsverdriet and K. Wandelt, J. Vac. Sci. Technol. 16,757 (1988). 